\title{
The metro and the city: interaction with the urban landscape in the new underground stations in Valencia 1995-2010
}

J. Pérez Igualada

Urbanism Department, Polytechnic University of Valencia, Spain

\begin{abstract}
The first stations of the Valencia subway lines were accessible by conventional metro entrances, stairs leading to an underground corridor or hallway, invisible from the street and from where you came, directly or through other corridors, to the platforms. In the new metro lines from the network of FGV - Ferrocarriles de la Generalitat Valenciana (Railways of the Regional Government of Valencia) built between 1995 and 2010 the architectural design of the stations is addressed in a different way - from design strategies that seek greater interaction with the public space and the urban environment. To expose these strategies of interaction with the urban environment, the paper uses as case studies several stations designed by the author, belonging to lines 3 and 5 of the Valencia Metro network.

Keywords: transportation, architecture, subways, metro station, urban design, Valencia.
\end{abstract}

\section{From the metro entrance to urban space: access to stations configured through site terrain modeling}

The architecture of stations is only a small part of the civil engineering work involved in the construction of a new metro line. However, this part is essential for the user, since the stations are spaces that serve to join the underground network, putting together two different levels or strata of the city, the network of streets and the subterranean. 
While the metropolitan railway runs on ground level, as in the peripheral or peri-urban areas of large cities, stations are buildings, clearly identifiable as an architectural volume, where we enter on one side, buy the ticket in the hallway, and exit on the opposite side to the platforms to board the subway wagon (Fig.1, Type 1).
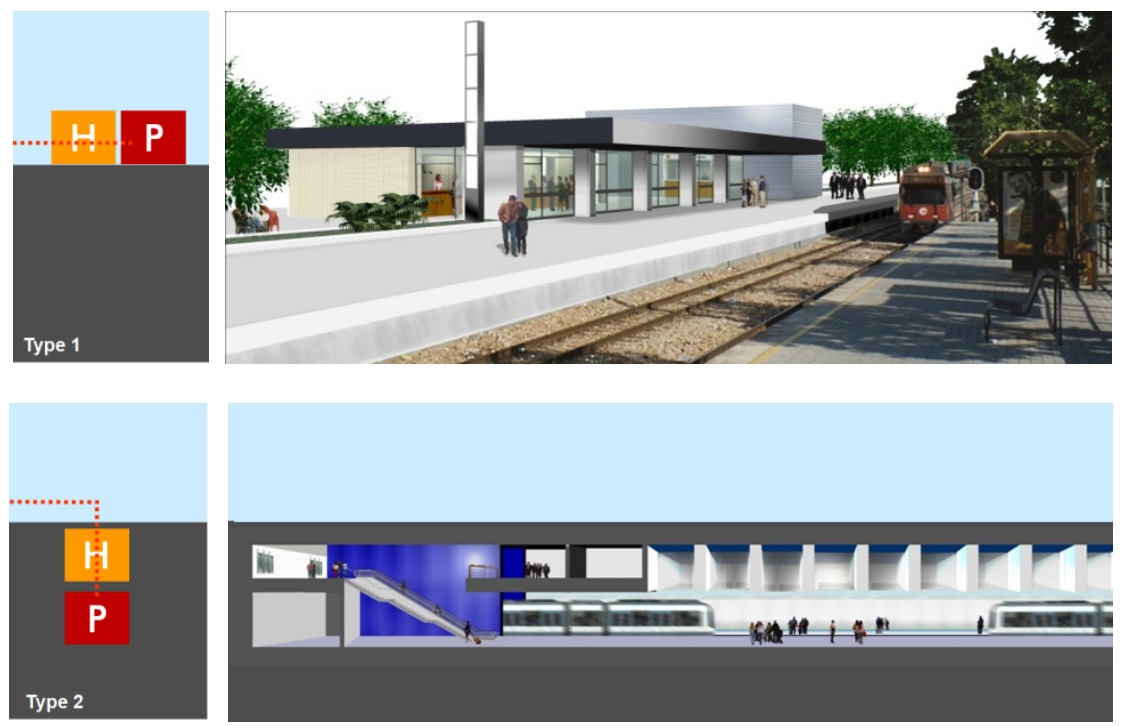

Figure 1: Access typologies in metro stations ( $\mathrm{H}$ : hallway. P: platforms). Type 1: Seminari Station. Metro Line 1, Valencia. Type 2: Joaquín Sorolla Station. Metro Line 1, Valencia.

This direct and legible access system is complicated when the metropolitan railway lines go into the central areas of cities and become subterranean. As a result, subway stations disappear as a building in the urban scene, and access to the platforms then becomes the stairs that descend from the ground level to the underground level (Fig. 1, Type 2). These stairs are located on the sidewalks of the streets, and require no special configuration of public space: only that they are wide enough. The entrances are identified by the user as metro entrances thanks only to the signaling elements, which have a uniform design in which the logo and other elements of corporate identity is repeated, as the elegant red circle with the word "Underground" in London or the modernist label with the word "Metropolitain" in Paris.

This conventional access system for metro stations, through stairs leading to an underground corridor or hallway, invisible from the street, was the one used in the first stations of the Valencia metro network of FGV - Ferrocarriles de la Generalitat Valenciana (Railways of the Regional Government of Valencia), corresponding to the central sections of Lines 1,2 and 3 of the network, built between 1988 and 1995. A lift connecting the street with the underground hallway was added to the stairs, allowing disabled access to the station. 

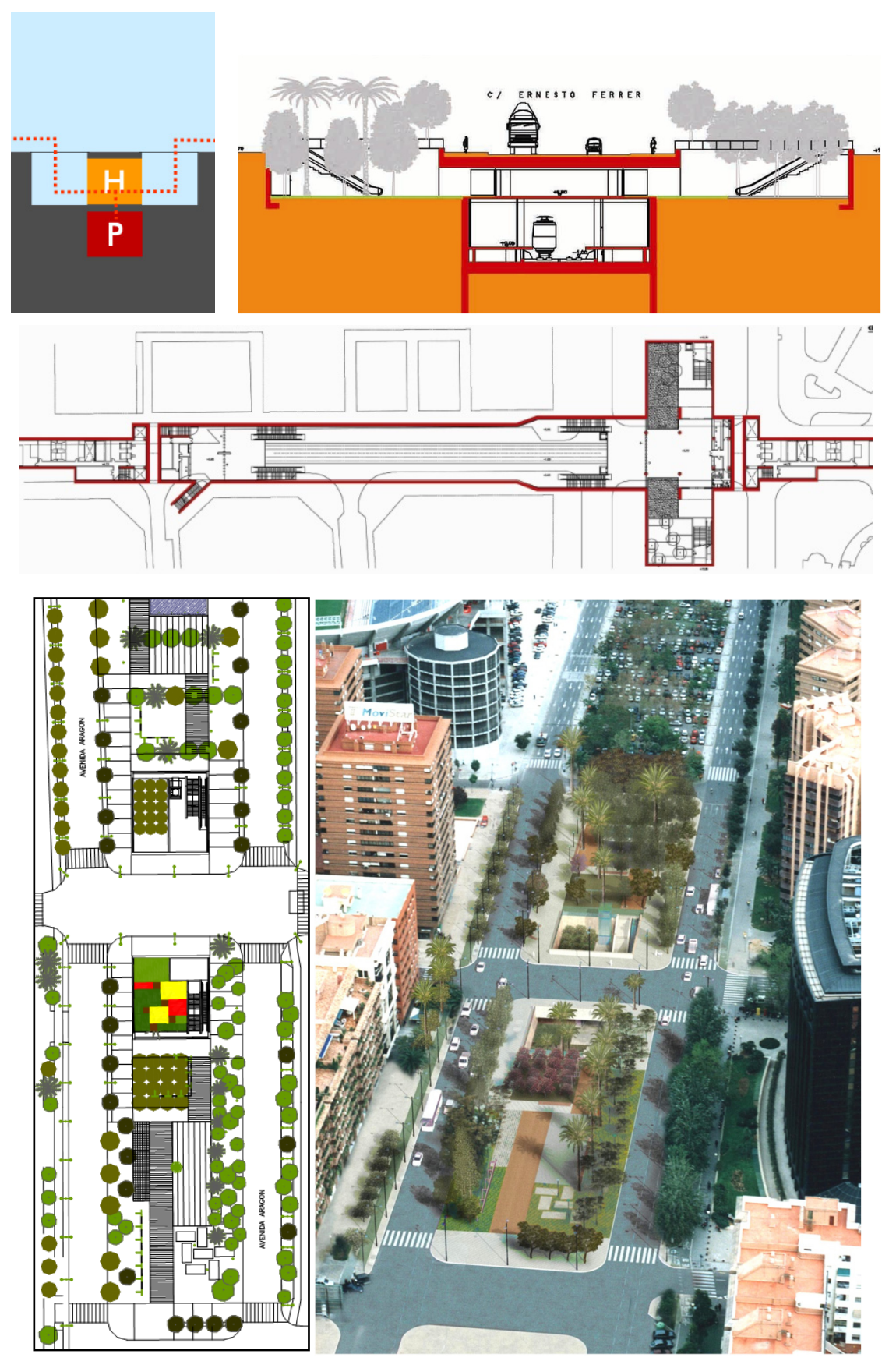

Figure 2: Aragón Station. Line 5 Metrovalencia. 
Nevertheless, in the new metro lines built between 2000 and 2010, the architectural design of the stations is addressed in a different way - from design strategies that seek greater interaction with the public space and the urban environment. These strategies, in addition to providing a specific design for each particular location within the city, have as a result a better accessibility for the users, as discussed below.

The first stations in the Valencia metro network designed with this new approach correspond to Line 5, which links the city waterfront and Manises Airport. These stations are Aragon and Ayora, included in the section of this line that was put into service in 2003, which starts in the Alameda station and ends near the Garden of Ayora [1].

In this stretch we can find three stations (Aragon, Amistat and Ayora) responding to the same type of plan and longitudinal section. They are placed as close as possible to the surface, and consist of two levels, with the platforms in the lower level and the primary and secondary hallways in the upper one. Both hallways have been designed as mezzanines located at the end of the platforms, so they allow us to perceive the entire inner space. However, each station has specific characteristics that derive from their particular urban environment.

Thus, Amistat station, being situated on a boulevard whose central pedestrian way is narrow, has been designed with conventional metro entrances, similar to those found in metro lines previously built in Valencia. Instead, in Aragón and Ayora stations the design exploits their location, with wide adjacent open spaces, to create through terrain modeling access spaces that are no longer a simple metro entrance but spaces that although placed at the same below ground level than the underground hallway can be considered as true urban spaces integrated with its surroundings.

The route of Line 5 crosses perpendicular to Aragon Avenue, a boulevard with its central promenade occupied by parking lots, because of its proximity to the Valencia football club stadium. Aragon station was designed so that its main entrance coincides with the axis of the Avenue. This entrance consists of two large patios or plazas below ground, 20×20 meters long, from which you can access the main lobby on their north and south fronts. The large central space of the boulevard section is recovered as a pedestrian walkway leading to the patios, placed on either side of the junction with the cross street of Ernesto Ferrer, under which the tunnel line runs.

Thus, access to the station is no longer a simple metro entrance but a public space, as patios provide a seamless connection between the inside and its urban environment. The transition between the hallway and the outside becomes much more enjoyable and readable since in our ascent from the platforms we can perceive on either side of the lobby the transparency crosswise and natural light that the glass facades which are open to the patios provide, clearly showing us where the exits are, and allowing us to also glimpse the skyline of the nearby buildings and know if the day is rainy or sunny.

So, a traditional urban element in Mediterranean cities, the patio, is integrated in the design of a metro station, a highly technological element of the public transport infrastructure. 

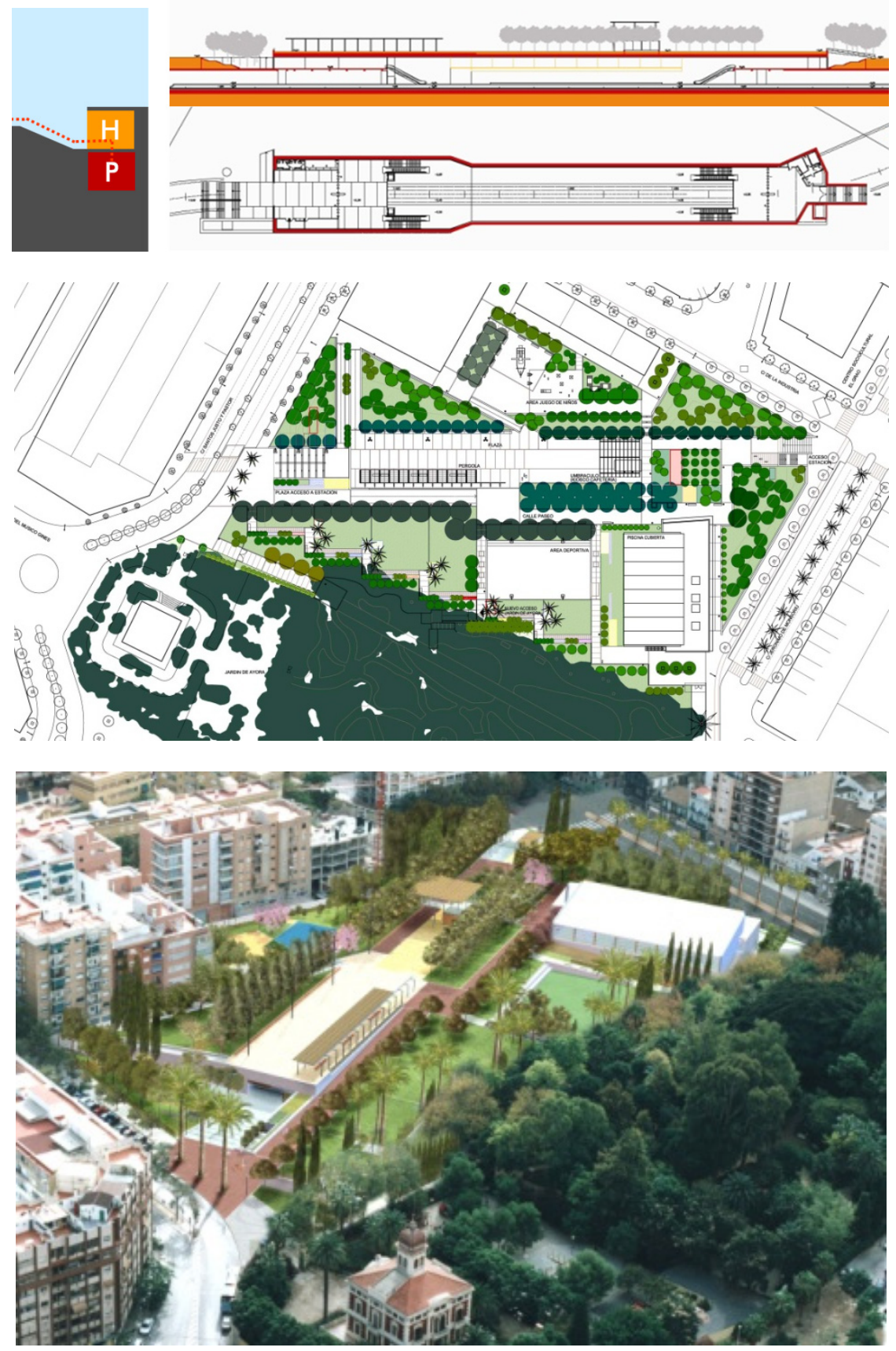

Figure 3: Ayora Station. Metro Line 5, Valencia. 
The layout of line 5 westward crossed in diagonal a planned neighborhood park, adjacent to the existing Garden of Ayora, a protected historic green space, of great historical value, which houses a XIX century small palazzo and a monumental plant mass formed by different species of large trees.

The planning option chosen was to place the new metro station under the neighborhood park. This option provided enough open spaces, through terrain modeling, to configure the entrance to the station as public space, integrated with the new planned park and the existing Garden of Ayora.

Thus, access to the main hallway of the Ayora station occurs from the north, near the palazzo, through a landscaped plaza that leads down a wide stairway or ramp at the front of the station, whose roof level is raised $1.10 \mathrm{~m}$ above street level.

The Garden of Ayora obviously assumes center stage in the whole composition, because the stunning green front of its woods is a major reference element in the urban design of the new neighborhood park created on the metro station. In the design any imitation of the Garden of Ayora has been avoided, a small scale and intimate nineteenth-century park with narrow meandering paths and parterres surrounded by hedges, since this would only achieve duplicity, and would not bring anything new to the leisure facilities associated to public green spaces existing in this part of the city.

Therefore, the new neighborhood park is planned so that it complements the Garden of Ayora, providing those spaces and facilities of a current equipped public park, that the historic garden cannot assume inside: a plaza a kiosk-bar, sports facilities, playgrounds and even an indoor swimming pool.

In designing the park, the backbone of the whole composition is a street or walkway that links the opposite corners of the site. This street-walk, located in tangential position to the underground station, is not a simple rectilinear axis from side to side, but it is projected seeking an effect of variety and closing of visual sequences, achieved through offsetting and reinforced by tree alignments and wooded areas.

The central space of the new park is tangent to the street-walk: a large elongated plaza located on the station roof, designed as an elevated plateau with respect to the surrounding streets. This plaza, which looks out onto a balcony on one side to the station main entrance space, is an excellent viewpoint over the Garden of Ayora, as well as a paved multifunctional space, with a good size both for daily use and for special events such as the July fair.

The plaza is equipped with two architectural elements: a pergola and a kiosk with an "umbráculo" (a shaded roof), both with a wooden ceiling and light steel structure. The pergola frames the view to the Garden of Ayora, while spatially separates the plateau from the adjacent street-walk. The shaded roof and the kiosk located under it, together with a formal grove of orange trees planted very close to each other, create a permeable boundary on the south side of the plaza. From the central plateau, the park gently descends to the Garden of Ayora and the surrounding streets, through a series of sloping meadows whose contour is adapted to the geometry of the site perimeter. 

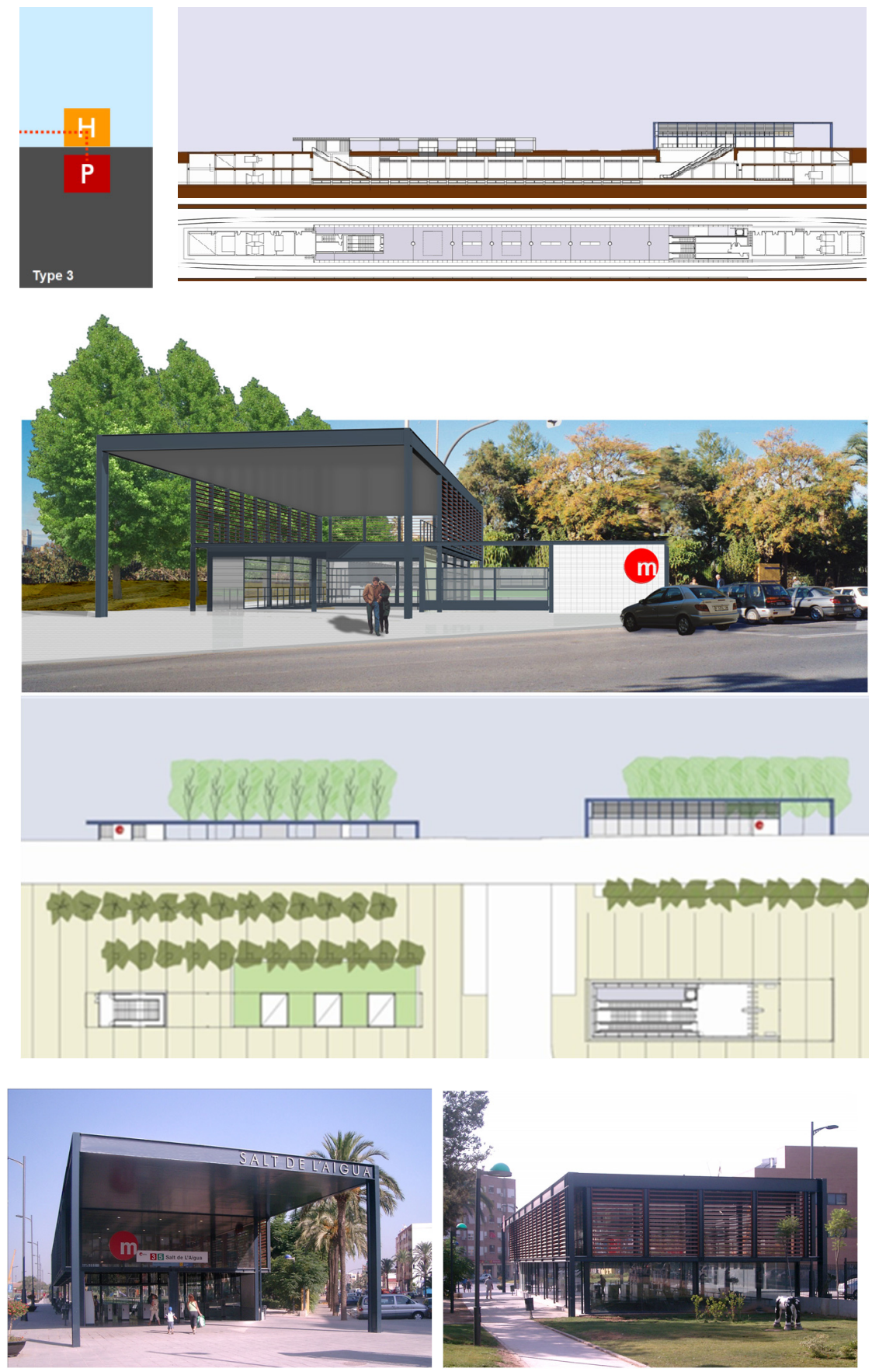

Figure 4: Metro stations. Line 5, Valencia, West branch. 


\section{Metro stations as emerging landmarks from the world of underground rail transport: the entrance pavillion at street level}

The stations of Aragon and Ayora, as we have seen, have access spaces that are no longer simple metro entrances, but spaces that although located below ground, are designed as urban spaces. Thanks to them, the metro stations hallways, despite being underground, have a facade to the outside, which allows direct entry of natural light. This is the first step in achieving that underground stations play a significant role as a visual reference in the urban landscape.

The next step in this process is taken in the stations planned for the extension of Line 5 of Metrovalencia to the west (section Mislata - Quart de Poblet Manises - Airport, 2004-2007) and the east (Maritimo-Serrería station, 2005), as well as for the new underground path of Line 3 passing through the town of Alboraya (Alboraya-Peris Aragó station, 2004-2010) and involves the creation of a new type of metro station in Valencia, with its hallway designed as an entrance pavilion at street level [2].

In this type, stations are located as close as possible to the surface, and consist of two levels, a lower one where the platforms are located, and an upper one located at street level, where the entrance pavilion can be found at one end of the platforms and an emergency exit on the opposite end.

The entrance pavilion allows metro stations in Line 5 west branch to retrieve the character of a public building and the role of visual reference in the urban landscape that the old stations of commuter rail lines had, according to its importance as elements that interconnect the towns of the metropolitan area of Valencia and connect all of them to the central city.

The entrance pavilion gives architectural uniqueness to Marítimo-Serrería station, which is consistent with its unique character from the railway standpoint, since it is an underground interchange station between metro and tram, where Tram Line 4 (Coastal Tram), runs on the surface through the maritime quarter of Cabanyal, descending through a ramp to the underground level platforms, where the exchange with metro Line 5 occurs.

Stations with entrance pavilion at street level in Valencia metro network, although designed specifically for each location, share common features in terms of accessibility, integration into the urban environment and outdoor and indoor architectural design.

With regard to accessibility, the main virtues of this new model of station area are as follows:

a) Direct access to the hallway from the street: The hallway is at street level, so access to it is performed directly, without having to go downstairs as in conventional metro entrances.

b) Common access for all users: All users access the station on the same entrance, (i.e. the door that connects the hallway to the street) avoiding segregate access for people with disabilities. 

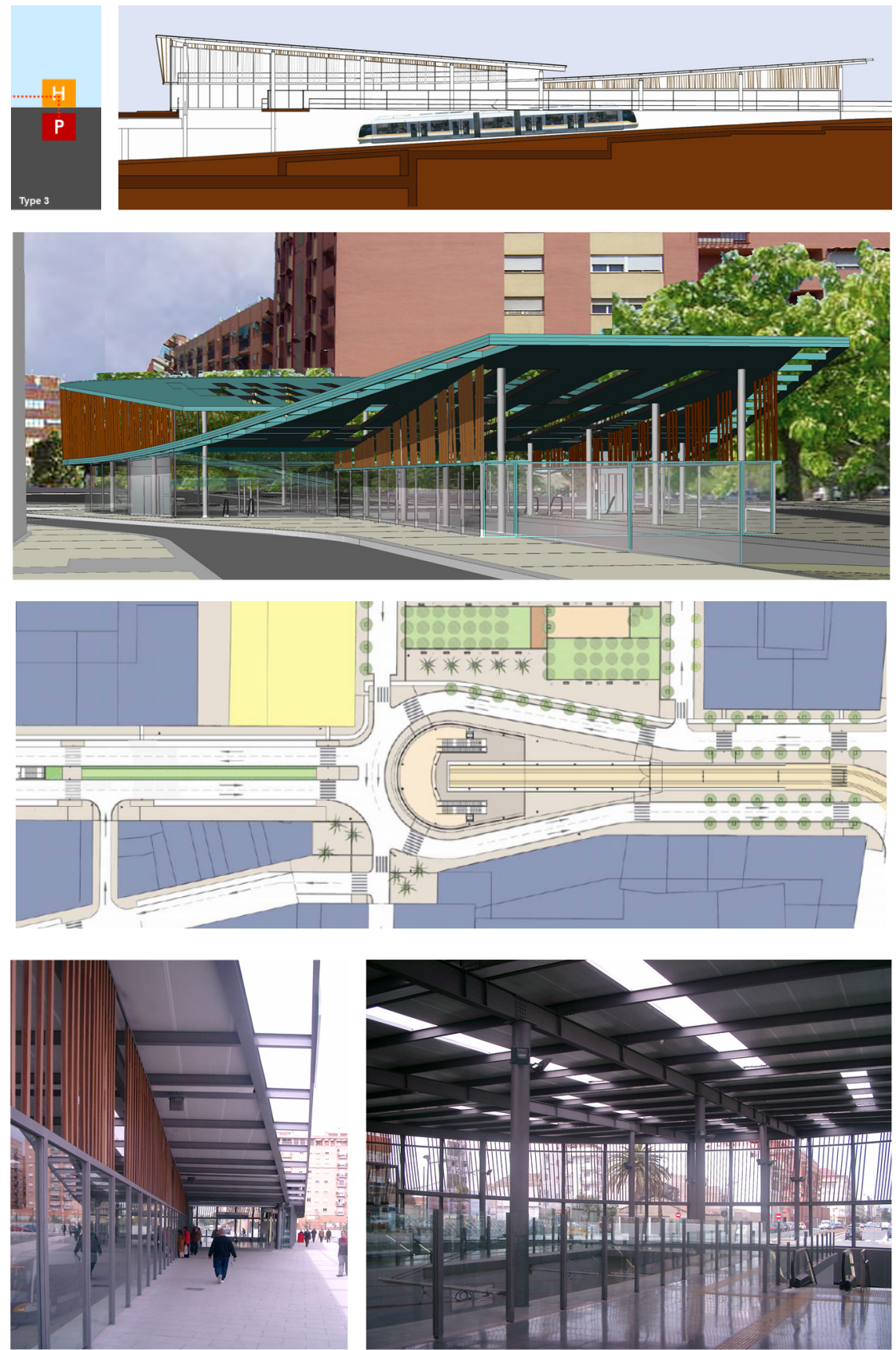

Figure 5: Marítimo-Serrería Station. Metro Line 5 Valencia, east branch. 
c) Platform level close to street level: The location of the platforms nearest as possible to the surface minimizes the vertical distance to be saved, preventing the traveler from having to use stairs that are too long.

As for the integration into the urban environment, the choice for a ground level entrance pavilion means that an appropriate location of the stations has previously been chosen, to guarantee that the pavilion surrounding public spaces are large enough to configure an access integrated in the urban landscape.

In the stations of the western section of Line 5 (Faitanar, Quart de Poblet, Salt del Aigua, Manises, Rosas) the main facade is located under a large atrium or covered porch open to a square or a large public space. This atrium extends the roof 10 meters in front of the glazed entrance façade, as a "palium" that protects it and configures a special urban space, a covered area of transition between the inside and the outside.

In Maritimo-Serrería station, this transition space takes the form of a large canopy, which extends enough to cover the tram descent ramp, which is thus integrated within the volume of the pavilion, so that its visual impact on the urban scene is minimized.

Alboraya-Peris Aragó station urban environment is an area of about $30 \mathrm{~m}$ wide and $200 \mathrm{~m}$ long that was previously fragmented by the railway layout of the former surface metro line. This space becomes now a landscaped plaza that ends the new green axis created in the site previously occupied by the tracks. The small distance between the ground and the roof slab of the underground station, which hinders the landscaping, leads to the design proposal of a plaza structured through the architectural elements of the station.

The elements of the Alboraya-Peris Arago station that emerge above ground level are the entrance pavilion, the emergency exit pavilion and a pergola. The entrance pavilion has two distinct volumes, which occupy two strips parallel to the layout of the platform. The entrances and tickets cancellation lines are located in the highest volume, open at both ends. The adjacent volume, of lesser height and blind ends, harbors the platform air renewal void, which is brought to the roof, and also hosts the control module, the elevator and the stairways, housed in large voids which function as skylights for the platform level. This lower built structure is connected with the emergency exit pavilion by a pergola that provides shade to the plaza. A common roof finishing and a uniform structural rhythm give architectural unity to the different elements encompassed in this strip.

The architectural design of the entrance pavilions, though specific to each particular urban environment as we can see, is nevertheless based on common project criteria for all the stations.

First, it's a common design goal to create an open and legible architectural space. To do this, transparency between the inside and the outside of the entrance pavilion is a positive value, both from the point of view of safety (to avoid visual barriers) as for an easy identification of the urban environment (by the user who leaves the station) and the interior elements (for the user who approaches it). 

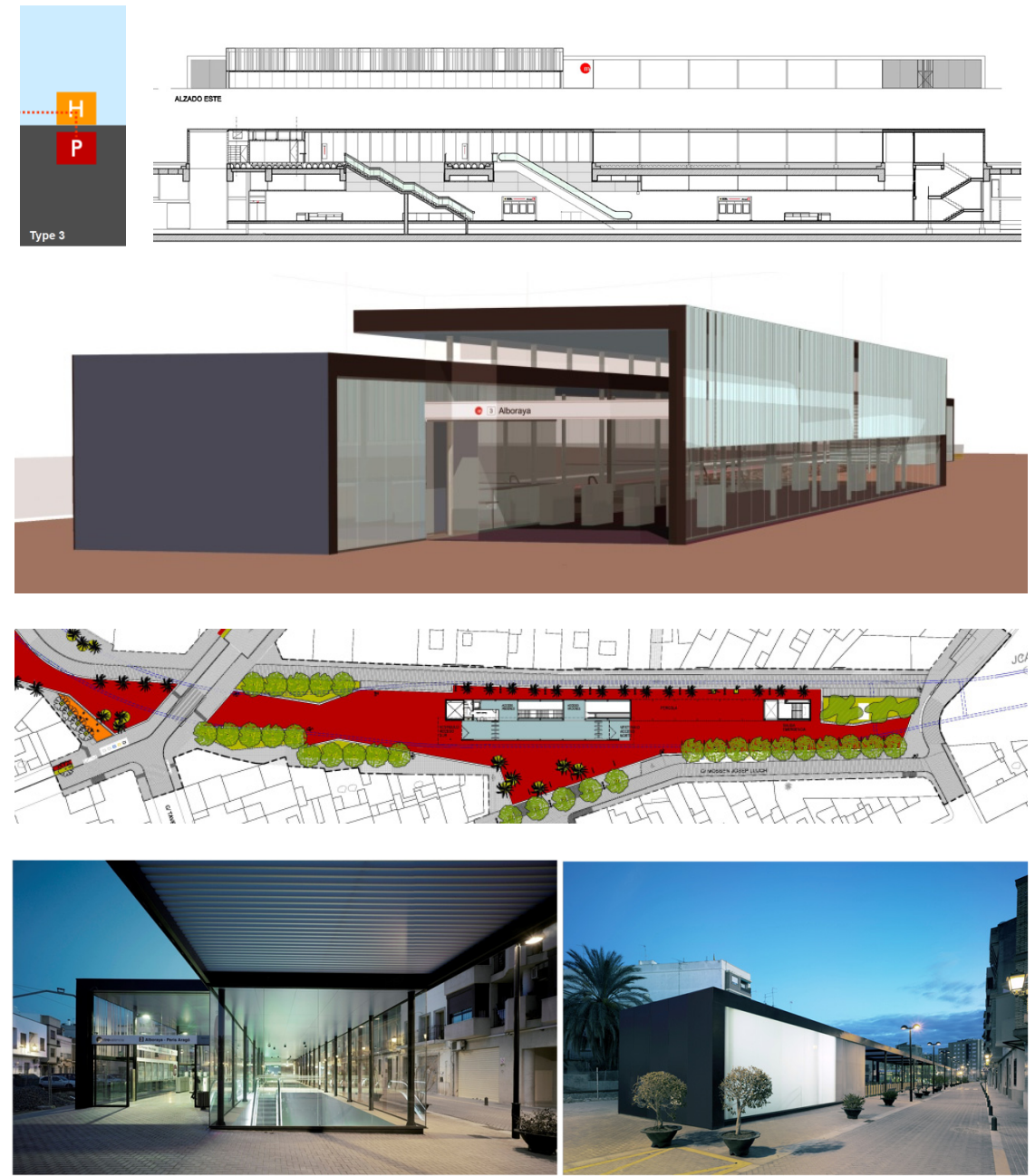

Figure 6: Alboraya-Peris Aragó Station. Metro Line 3, Valencia. (Photos: David Frutos.)

A second common feature in the stations' architectural design is the search for user comfort. To obtain it in our Mediterranean climate is essential to provide adequate protection against excessive sunlight.

The combination of these two aspects (sun protection and transparency) leads to projected architectural solutions, in which we have:

a) An opaque roof, which produces abundant shade. Glazed roofs, thus, are avoided, because they are problematic in hot spots with little rain, both in terms of comfort (greenhouse effect) and maintenance (cleaning).

b) Glass facades around the perimeter of the hallway. 
c) An overlapped sunscreen, made of different materials: wood slats in Maritime-Serrería station, steel slats in the in the western section of Line 5 stations and a glass surface treatment in Alboraya-Peris Aragó station. The sunscreen occupies only the upper half of the elevation, so that the transverse visual permeability and transparency in the lower half of the facade is preserved.

The design of interior spaces has been made also seeking interaction with the urban environment. To do so, the elements of vertical communications (elevator, fixed and mobile stairs) have been placed in double height voids that connect visually the street and platform levels. These voids, in various forms (a huge single rectangular void in the stations in the west section of Line 5, a circular one in Marítimo-Serrería, several serial rectangular voids in Alboraya-Peris Aragó), provide natural light to the lower level of the station and make the path to enter or exit the station more pleasant, clear and legible.

\section{Conclusions}

We have exposed some strategies of interaction with the urban environment for metro stations, using as case studies several stations belonging to lines 3 and 5 of the Valencia Metro network. We can highlight from the analyzed case studies two main practices or methods useful to be applied in similar urban contexts: the site terrain modelling to configure access spaces that, although located underground, are urban spaces integrated with its surroundings, and the design of an entrance pavilion located on the surface, at street level. Both methods require close collaboration between engineering and architecture project teams. We have also showed that these strategies, in addition to providing a specific design for each certain location within the city, have as a result a better accessibility and comfort for the users.

The detailed case studies analysis presented in the paper allows us to verify that through these design strategies metro stations can become emerging landmarks from the world of underground rail transport and instead of hiding under the streets, assume the importance of its role in the urban landscape as a means of sustainable public transport.

Note: All the case studies presented in this paper correspond to stations designed by the author. The complete credits and details of the projects can be found in the references. All images in the figures come from the author's archives, except where noted.

\section{References}

[1] CB Arquitectes Associats, Proyectos y obras 1988-2000. TC Cuadernos, 47, pp. 20-35, 2001.

[2] Pérez Igualada, J., Arquitectura para el transporte. Universitat Politècnica de València: Valencia, 180 pp., 2010. 